\section{Research Square}

\title{
Pyogenic Lung Abscess in an Infectious Disease Unit, a 20-year Retrospective Study
}

\section{Thomas Maitre ( $\nabla$ thomas.maitre5@gmail.com )}

UPMC Faculte de Medecine Site Pitie-Salpetriere https://orcid.org/0000-0002-5463-336X

\section{Vichita OK}

Hôpital Avicenne: Hopital Avicenne

\section{Ruxandra CALIN}

HospitalTenon: Hopital Tenon

\section{Ludovic LASSEL}

HospitalTenon: Hopital Tenon

\section{Ana CANESTRI}

HospitalTenon: Hopital Tenon

\section{Michel DENIS}

Hôpital Tenon: Hopital Tenon

Mohammed HAMIDI

Hôpital Tenon: Hopital Tenon

\section{Sebastian TAVOLARO}

Hopital Tenon Service Radiologie

\section{Charlotte VERDET}

Hospital Saint-Antoine: Hopital Saint-Antoine

\section{Antoine PARROT}

Hôpital Tenon: Hopital Tenon

Jacques CADRANEL

Tenon Hospital Pneumology Service: Hopital Tenon Service de Pneumologie

\section{Gilles PIALOUX}

Hôpital Tenon: Hopital Tenon

\section{Research}

Keywords: pyogenic, lung, abscess, haematogenous, bronchogenic

Posted Date: December 2nd, 2020

DOI: https://doi.org/10.21203/rs.3.rs-116733/v1 
License: (c) (i) This work is licensed under a Creative Commons Attribution 4.0 International License. Read Full License 


\section{Abstract}

Rationale: Pyogenic lung abscesses are rare and poorly described infections. This study aimed to describe their prognostic factors.

Methods: We retrospectively included all patients hospitalized between January 1st, 1998 and June 1st, 2018 , with a IDC-10 diagnosis of pyogenic lung abscess, from the Diamm ® based medical records (Micro6, Nancy; France). Parasitic, mycological, or mycobacterial lung abscesses were excluded.

Results: A total of 64 patients were included. Abscesses were associated with immunosuppression in 28 patients, including HIV infection and immunosuppressive therapy for 8 and 12 patients, respectively. Bacterial identification was obtained for 36 patients. Nine patients (14\%) developed lung abscesses after haematogenous dissemination. They differed from bronchogenic abscesses by their younger age $(p=0.03)$, the absence of smoking or emphysema $(p=0.05), S$. aureus $(p=0.001)$ or Streptococcus $s p p$ $(p=0.05)$ isolation, and the smaller size of their abscess $(p=0.02)$. Overall, evolution was marked by radiological sequelae, relapse, and death. Radiological sequelae occurred more frequently during the course of bronchogenic abscesses $(p=0.02)$, particularly when they spontaneously discharged $(p=0.04)$. Relapses were more frequent in patients with emphysema $(p=0.04)$ and when $H$. influenzae was isolated $(p=0.04)$. In multivariate analysis, poor outcomes, including death, sequelae, and relapse occurred more frequently in patients who had bronchogenic abscess $(p=0.02)$, and in those who received antibiotics during less than 6 weeks $(p=0.05)$.

Conclusion: Duration of antibiotic treatment of less than six weeks and bronchogenic presentation were globally associated with poor outcome of pyogenic lung abscesses. These data should be considered when proposing guidelines for the care of pyogenic lung abscesses.

\section{Introduction}

Lung abscesses are defined as necrotic cavitary lesions containing pus in the pulmonary parenchyma, leading, after formation of bronchopulmonary fistula, to an air-fluid level inside the cavity [1-3]. They are usually caused by pyogenic bacteria, particularly anaerobic bacteria, Staphylococcus aureus, and aerobic Gram-negative bacteria [4-7]. In the pre-antibiotic era, mortality from lung abscesses was approximately $75 \%$ without treatment [8]. Lung-abscess mortality decreased to $20-35 \%$ with open drainage [9] and less to $10 \%$ with antibiotic therapy [9-12]. Antibiotic treatment, with or without drainage, is currently the standard of care, but up to now no specific guidelines defines the duration of antibiotic treatment. Some studies have shown that it may require 3 to 20 weeks to cure a lung abscess by antibiotic treatment [13, 14]. Globally, mortality rate of lung abscesses varies from 1 to $20 \%$ depending on study periods and patient's history $[4,6,9-13,15-17]$ and thus deserves to be better defined. Finally, there is a lack of data regarding other outcome factors, such as radiographic sequelae or relapse in adult lung abscesses.

Our objective was to assess clinical and radiological presentation, bacterial identification and prognostic factors, over the 20-year period of the study, to suggest improvements in the care of patients with lung 


\section{Methods}

\section{Study population}

We retrospectively included all patients over 18 years of age hospitalized between January 1st, 1998 and June 1st, 2018 in the infectious disease unit of Tenon University Hospital (Paris, France) with a diagnosis of pyogenic lung abscess. Consecutive cases of lung abscess were identified by a retrospective search of medical discharge summaries for the 20-year period with the appropriate International Classification of Diseases 10 (ICD-10) code.

\section{Data collection}

A retrospective review of medical records of all identified cases was performed. All cases of lung pyogenic abscess with clinical and radiological evidence were included; parasitic, mycological, and mycobacterial lung abscesses were all excluded from the study. Lung abscess was defined as a necrotic lung cavitary lesion of more than $2 \mathrm{~cm}$ in diameter. Data were collected using a standardized form. General data collected were: patient age, gender, country of birth, HIV infection, other immunosuppressive conditions, tobacco use, alcoholism, diabetes mellitus, dental decay, aspiration risk, oro-tracheal intubation, tracheostomy, sinusitis, lung cancer, emphysema, bronchiectasis, broncho-oesophageal fistula, pulmonary embolism, and pulmonary contusion. The time between the first symptoms and the diagnosis of lung abscess was also recorded. Lung abscesses were considered to be acute when the time between the first symptoms and diagnosis was less than six weeks and chronic when it was equal to or more than six weeks as in another study [14]. Abscesses secondary to bacteraemia occurring from another entry site defined haematogenous lung abscesses. Other abscesses were considered to be bronchogenic. Radiological investigations defined the number of abscesses, pulmonary lobe location, pleural disease, and the largest abscess diameter. Bacterial identification data was also recorded. Therapeutic data collected included the antibiotic molecules administered, treatment duration, open drainage, surgical management, and spontaneous discharge. Outcome data collected comprised mortality, relapse, and radiological sequelae. Relapse was defined as a new lung abscess occurring in the same location as the previous disease after the end of antibiotic treatment. Radiological sequelae were defined as cavitary lesions, bronchiectasis, or infiltrates persistent in the location of the lung abscess 2 months after treatment ended.

\section{Statistics}

The patients' characteristics were explored using classical descriptive parameters. Univariate analysis comparing the two patient groups (bronchogenic vs. haematogenous abscess) was performed using the Chi2 test for qualitative variables (or the Fisher's test when conditions for the Chi2 test were not met). Quantitative variables were compared using the Student's t-test (or the Wilcoxon's test when the Student's 
test conditions were not met). These analyses were performed using Stata ${ }^{\circledR} 14$ software. Differences were considered statistically significant when the P-value was $\leq 0.05$.

For the outcome's analysis, we considered the composite "poor outcome" criterion defined as death, relapse and/or radiological sequelae. Univariate and multivariate analyses to identify factors associated with the outcome were performed using logistic regression model. Variable selection for multivariate logistic regression model was based on significance from univariate analysis as pre-screening $(P<0.25)$. The odds ratio $(O R)$ along with $95 \%$ confidence interval $(95 \% \mathrm{Cl})$ were calculated. P-value associated with the models' variables were reported with the threshold of statistical significance set at $5 \%$. These analyses were performed using R software [18].

\section{Ethics}

Data were recorded in a clinical database (DIAMM-G ${ }^{\circledR}$, Micro-6, Nancy, France). The National Commission on Informatics and Liberties (CNIL) approved the database used in this study. The study protocol is conformed to the ethical guidelines of the 1975 Declaration of Helsinki (revised in Edinburgh in 2000), as reflected by a priori approval by the institution's human research committee.

\section{Results}

\section{General description of the patients}

We retrospectively included a total of 64 patients hospitalized between January 1st, 1998 and June 1st, 2018 with at least one pyogenic lung abscess. The general characteristics are summarized in Table 1. The patients were predominantly male $(n=47 ; 73.4 \%)$. The median age at lung abscess diagnosis was 48 years [IQR $=43-58]$. Overall, 34 patients $(53.1 \%)$ were born in France. 
Table 1

General characteristics and radiological presentation of patients with pyogenic lung abscesses

\section{Male $n(\%)$}

Age in years, median [IQR]

Country of birth $\mathrm{n}(\%)$

France

Africa

Middle East

Asia

Americas

Former USSR

Immunocompromised conditions n (\%)

HIV

Immunosuppressive therapy $\mathrm{n}(\%)$

Diabetes mellitus $\mathrm{n}(\%)$

Lung cancer $\mathrm{n}(\%)$

Smoking $\mathrm{n}(\%)$

Alcoholism n (\%)

Dental decay $\mathrm{n}(\%)$

Aspiration risks n (\%)

Orotracheal intubation $\mathrm{n}(\%)$

Tracheostomy n (\%)

Sinusitis n (\%)

Emphysema n (\%)

Broncho-oesophageal fistula n (\%)

Pulmonary embolism n (\%)

Lung contusion $\mathrm{n}(\%)$

Bronchiectasis n (\%)

Haematogenous dissemination $\mathrm{n}(\%)$

Multiple abscesses n (\%)
$47(73.4 \%)$

48 [43-58]

$34(53.1 \%)$

$20(31.2 \%)$

$1(1.6 \%)$

$4(6.2 \%)$

$1(1.6 \%)$

$2(3.1 \%)$

$28(43.7 \%)$

8 (12.5\%)

12 (18.7\%)

7 (10.9\%)

$3(4.7 \%)$

47 (73.4\%)

25 (39.1\%)

22 (34.4\%)

9 (14.1)

$1(1.6 \%)$

$3(4.7 \%)$

$5(7.9 \%)$

$14(2.2 \%)$

$1(1.6 \%)$

$1(1.6 \%)$

$1(1.6 \%)$

$1(1.6 \%)$

9 (14.1)

17 (26.6\%) 
Pleural effusion $\mathrm{n}(\%)$ $24(37.5 \%)$

Abscess diameter, mean in $\mathrm{mm}$ (+/- SD) $55.7(+/-28.1)$

USSR: Union of Soviet Socialist Republics; RUL: Right Upper Lobe; LUL: Left Upper Lobe; LLL: Left Lower Lobe; RLL: Right Lower Lobe, ML: Middle Lobe.

\section{Lung abscess underlying conditions}

The underlying conditions are detailed in Table 1. Immunosuppression was observed in 28 patients (43.7\%), and included HIV infection $(n=8,12.5 \%)$, diabetes mellitus $(n=7,10.9 \%)$, and others $(18.7 \%)$. Underlying conditions were smoking for 47 patients (73.4\%), alcoholism for 25 (39.0\%), and dental decay for 22 (34.4\%); other conditions were less frequent: emphysema for 14 patients (21.9\%), aspiration risks for $9(14.0 \%)$, sinusitis for 5 (7.9\%), lung cancer for $3(4.7 \%)$, and tracheostomy for $3(4.7 \%)$. Bronchiectasis, pulmonary embolism, and lung contusion were each observed in one patient $(1.6 \%)$.

\section{Clinical and radiological presentations}

The lung abscess symptom onsets were acute in 44 patients (68.7\%). Seventeen patients (26.6\%) had multiple lung abscesses. Radiographic analyses showed the right lower lobe $(R L L)$ to be the more frequent location $(n=21,32.8 \%)$. Multi-lobe abscesses were more frequently observed in acute presentation (8 $(18.2 \%)$ vs. $0(0 \%) ; p=0.04)$. Pleural effusion was more frequent in nonimmunosuppressed patients $(18(50.0 \%)$ vs. $6(23.1 \%) ; p=0.05)$. The mean of the largest abscess diameter was $55.7 \mathrm{~mm}(+/-28.1)$. The abscess diameters appeared larger when patient had underlying chronic sinusitis $(p=0.02)$.

Nine patients (14.1\%) developed lung abscesses after haematogenous dissemination, whereas the others developed lung abscesses after bronchogenic dissemination. The main differences between bronchogenic and haematogenous lung abscesses are reported in Table 2. Patients with haematogenous abscesses were younger (45 years [29-50] vs. 48 years [44-60]; $p=0.03$ ). Multi-lobe abscesses were more frequently observed in patients with haematogenous abscesses $(5(55.5 \%) v s .3(5.4 \%) ; p=0.01)$. Smoking and emphysema conditions appeared more frequently in patients with bronchogenic abscesses $(p=0.05)$. The abscess diameters were larger when they had bronchogenic origin $(59.8 \mathrm{~mm}+/-27.5 \mathrm{vs}$. $30.4+/-16.4, p=0.02$ ).

\section{Microbial identification}


The microbial agent responsible for the lung abscess was identified for $36(56.2 \%)$ patients. Bacteria were more frequently documented in immunosuppressed patients (11 (92.7\%) vs. $25(48.1 \%) ; p=0.006)$, those with underlying aspiration risks (8 $(88.9 \%) v s .28(50.9 \%) ; p=0.03)$, and when open drainage was performed (8 $(88.9 \%)$ vs. $28(50.9 \%) ; p=0.03)$. The microbial agents isolated in lung abscesses are detailed in Table 3. The four more frequently identified bacteria were Staphylococcus aureus $(n=11)$, Streptococcus spp. $(\mathrm{n}=7)$, Pseudomonas aeruginosa $(\mathrm{n}=6)$, and Haemophilus influenzae $(\mathrm{n}=3)$. Streptococcus spp. were more frequently documented when pleural effusion complicated the lung abscesses (3 (12.5\%) vs. $0(0.0 \%) ; \mathrm{p}=0.05)$, in women (5 (29.4\%) vs. $2(4.2 \%) ; \mathrm{p}=0.01)$, and in haematogenous lung abscesses $(3(33.3 \%)$ vs. $4(7.3 \%) ; p=0.05)$. S. aureus was more frequently identified when the abscesses were multiple (7 (41.2\%) vs. $4(0.8 \%) ; p=0.005)$, multi-lobe $(4(50.0 \%) v s .7$ $(12.5) ; p=0.02)$, or of haematogenous origin (6 (66.7\%) vs. $5(9.0 \%) ; p=0.0001)$. P. aeruginosa was more frequently isolated in patients with tracheostomy $(2(66.7 \%) v s .4(6.6 \%) ; p=0.02)$ and those with aspiration risks (3 $(33.3 \%)$ vs. $3(5.4 \%) ; p=0.03)$. Staphylococcus spp. and Streptococcus spp. were more frequently documented in haematogenous abscesses $(p=0.001$ and $p=0.05$, respectively), whereas microbial documentation appeared less frequent in bronchogenic abscesses $(p=0.003)$ (Table 2$)$. 
Table 2

Main differences between bronchogenic and haematogenous lung abscesses

\begin{tabular}{|c|c|c|c|}
\hline & $\begin{array}{l}\text { Bronchogenic } \\
\text { abscess }\end{array}$ & $\begin{array}{l}\text { Haematogenous } \\
\text { abscess }\end{array}$ & $\begin{array}{l}\mathrm{p}- \\
\text { value }\end{array}$ \\
\hline Patients & $55(85.9 \%)$ & $9(14.1 \%)$ & \\
\hline Age, median in years ([IQR]) & $48[44-60]$ & $45[29-50]$ & 0.03 \\
\hline HIV infection & $7(12.7 \%)$ & $1(11.1 \%)$ & n.s. \\
\hline Other immunocompromised conditions & $9(16.4 \%)$ & $3(33.3 \%)$ & n.s. \\
\hline Smoking & $43(78.2 \%)$ & $4(44.4 \%)$ & 0.05 \\
\hline Alcoholism & $24(43.6 \%)$ & $1(11.1 \%)$ & n.s. \\
\hline Diabetes mellitus & $7(12.7 \%)$ & $0(0.0 \%)$ & n.s. \\
\hline Dental decay & $17(30.9 \%)$ & $5(55.5)$ & n.s. \\
\hline Aspiration risk & $8(14.5 \%)$ & $1(11.1 \%)$ & n.s. \\
\hline Sinusitis & $3(5.4 \%)$ & $2(22.2 \%)$ & n.s. \\
\hline Emphysema & $14(25.4 \%)$ & $0(0.0 \%)$ & 0.05 \\
\hline RLL location & $15(27.3 \%)$ & $6(66.7 \%)$ & 0.03 \\
\hline Multiple lobe location & $3(5.4 \%)$ & $5(55.5 \%)$ & 0.01 \\
\hline Multiple abscess & $9(16.4 \%)$ & $8(88.9 \%)$ & 0.001 \\
\hline $\begin{array}{l}\text { Main abscess diameter, mean in } \mathrm{mm}(+/- \\
\text { SD) }\end{array}$ & $59.8(+/-27.5)$ & $30.4(+/-16.4)$ & 0.02 \\
\hline Microbiological identification & $27(49.1 \%)$ & $9(100.0 \%)$ & 0.003 \\
\hline Staphylococcus aureus & $5(9.1 \%)$ & $6(66.7 \%)$ & 0.001 \\
\hline Streptococcus spp. & $4(7.3 \%)$ & $3(33.3 \%)$ & 0.05 \\
\hline Pseudomonas aeruginosa & $6(10.9 \%)$ & $0(0.0 \%)$ & n.s. \\
\hline Mortality & $3(5.4 \%)$ & $0(0.0 \%)$ & n.s. \\
\hline Radiographic sequelae & $29(52.7 \%)$ & $1(11.1 \%)$ & 0.02 \\
\hline Relapse & $8(14.5 \%)$ & $0(0.0 \%)$ & n.s. \\
\hline Bad outcomes & $32(58.2 \%)$ & $1(11.1 \%)$ & 0.01 \\
\hline
\end{tabular}


Table 3

Microbial identification in patients with pyogenic lung abscess.

\begin{tabular}{|ll|}
\hline Microbiological identification n (\%) & $36(56.2 \%)$ \\
\hline Staphylococcus aureus n (\%) & $11(17.2 \%)$ \\
\hline Streptococcus pneumoniaen (\%) & $3(4.7 \%)$ \\
\hline Streptococcus anginosus n (\%) & $2(3.1 \%)$ \\
\hline Streptococcus sanguinis $\mathrm{n}(\%)$ & $1(1.6 \%)$ \\
\hline Streptococcus intermedius $\mathrm{n}(\%)$ & $1(1.6 \%)$ \\
\hline Haemophilus influenzae $\mathrm{n}(\%)$ & $3(4.7 \%)$ \\
\hline Pseudomonas aeruginosa $\mathrm{n}(\%)$ & $6(9.4 \%)$ \\
\hline Escherichia coli $\mathrm{n}(\%)$ & $1(1.6 \%)$ \\
\hline Klebsiella spp n (\%) & $2(3.1 \%)$ \\
\hline Enterobacter spp n (\%) & $2(3.1 \%)$ \\
\hline Legionella pneumoniae $\mathrm{n}(\%)$ & $1(1.6 \%)$ \\
\hline Prevotella baroniaen (\%) & $1(1.6 \%)$ \\
\hline Pasteurella multocida $\mathrm{n}(\%)$ & $1(1.6 \%)$ \\
\hline Hafnia alvei $\mathrm{n}(\%)$ & $1(1.6 \%)$ \\
\hline Gemella haemolysans $\mathrm{n}(\%)$ & $1(1.6 \%)$ \\
\hline
\end{tabular}

\section{Treatment and outcomes}

The treatment and outcomes are detailed in Table 4. All patients received antibiotics. The mean duration of antibiotic treatment was 5.0 (+/- 2.5) weeks. In addition, 11 patients benefited from a drainage procedure. Open drainage was performed in 9 patients and surgical management in 2. Open drainage was more frequently performed when pleural effusion complicated the lung abscess $(6(25.0 \%) v s .3$ $(7.5 \%) ; p=0.05)$ and in documented Streptococcus spp. lung abscesses (3 (42.9\%) vs. $6(10.5 \%) ; p=$ 0.05). Spontaneous discharge of the abscess occurred in 4 patients. Among the 64 patients treated with antibiotic treatment, $30(46.9 \%)$ received antibiotics for less than six weeks and $34(53.1 \%)$ for more than six weeks. The proportion of emphysema was higher in the group treated for less than six weeks (11 $(37 \%) v s .3(9 \%) ; p<0.01)$. Bacteria were more frequently identified in the group treated for more than six weeks $(23(67 \%)$ vs. $13(43 \%) ; \mathrm{p}=0.05)$.

Poor outcomes included mortality (4.8\%), relapse (12.5\%), and radiologic sequelae (46.9\%). Relapses were more frequent in patients with emphysema (4 (28.6\%) vs. $4(8 \%) ; \mathrm{p}=0.04)$ and in documented $\mathrm{H}$. influenza lung abscesses (2 (66.7\%) vs. $6(9.8 \%) ; p=0.04)$. Radiographic sequelae occurred more 
frequently in patients with bronchogenic abscesses (29 (52.7\%) vs. $1(11.1 \%) ; \mathrm{p}=0.02)$ (Table 2), those with spontaneous discharge (4 (100\%) vs. $26(43.3 \%) ; p=0.04)$, and when the abscesses were limited to one lobe (29 (96.7\%) vs. $27(79.4 \%) ; p=0.04)$. Globally, in univariate analysis, poor outcomes were more frequently observed in patients with underlying emphysema $(p=0.03)$. They were less frequently observed in haematogenous lung abscess $(p=0.03)$ and when the antibiotic treatment duration was over 6 weeks $(p=0.02)$. In multivariate analysis, the risk of poor outcomes was lower in patients who received more than 6 weeks of antibiotic treatment $(O R=0.31[0.09-0.96] ; p=0.05)$, and in patients suffering from haematogenous abscesses $(O R=0.07[0.00-0.48] ; p=0.02)$, but was not increased in patients with underlying emphysema $(\mathrm{OR}=1.64[0.32-9.77])$ (Fig. 1).

Table 4

Treatment and outcomes of patient with pyogenic lung abscess .

\begin{tabular}{|ll|}
\hline Treatment & - \\
\hline Duration of antibiotic treatment, mean in weeks (+/-SD) & $5.0(+/-2.5)$ \\
\hline Open drainage & $9(14.1 \%)$ \\
\hline Surgical management & $2(3.1 \%)$ \\
\hline Spontaneous discharge & $4(6.2 \%)$ \\
\hline Outcomes & \\
\hline Mortality & $3(4.8 \%)$ \\
\hline Radiographic sequelae & $30(46.9 \%)$ \\
\hline Relapse & $8(12.5 \%)$ \\
\hline
\end{tabular}

\section{Discussion}

There are no specific guidelines for the care of patients with lung abscesses, few and short series of such patients are reported in the literature $[6,12,13,17]$. Patients who develop lung abscesses make up a very heterogonous population. In the present study, we distinguished pragmatically two main groups of patients with a specific presentation, microbial identification, and prognosis. The first one consists of the youngest patients, who developed lung abscesses associated with haematological dissemination, i.e. positive blood cultures from another entry site. Their radiological presentations consisted of multiple abscesses in multiple lobe locations of smaller size than bronchogenic abscesses. The main bacteria associated with these presentations were Gram-positive cocci, particularly S. aureus and Streptococcus spp. Thus, we recommend that empiric antibiotic treatment should consist of bactericidal molecules against Streptococcus and Staphylococcus spp. as soon as haematogenous presentation is suspected. Moreover, in a nosocomial context, the therapeutically spectrum should include methicillin-resistant $S$. aureus. We suggest empiric treatment with amoxicillin and clavulanic acid for community-acquired [19, 
20], and vancomycin for nosocomial [21] haematogenous lung abscesses. The second group is composed of the oldest patients and corresponds to those developing lung abscesses with a bronchogenic presentation. Their abscesses were more frequently unique, limited to one lobe, and larger than those observed in the haematogenous presentation. Patients who developed bronchogenic lung abscesses appeared to have a history of smoking and previous emphysematous lung disease. Globally, patients with bronchogenic lung abscesses had a worse prognosis than those with haematogenous lung abscesses in our study. Among patients with a bronchogenic presentation, $P$. aeruginosa was more frequently isolated in patients with aspiration risks and, more particularly, tracheostomy. Therefore, we recommend including Pseudomonas spp. in the spectrum of empiric antibiotic treatment proposed for patients with aspiration risk and suggest empiric treatment with piperacillin and tazobactam to maintain anti-anaerobic activity [22].

The median age of the patients (48 years) and large proportion of smoking history (73\%), as well as the frequency of alcoholism (39\%), dental decay (34\%), HIV infection (12\%), diabetes mellitus (11\%), and aspiration risks (14\%) of our studied population are similar to those reported in previous work [23-26]. Nevertheless, we observed a smaller proportion of lung cancer (5\%), emphysema (2\%), and bronchiectasis $(2 \%)$ than in the other studies $[6,12,13,17]$. Just under half of the patients were immunosuppressed. Immunocompetent patients developed lung abscesses, which were more frequently complicated by pleural effusion. These data support the previous results of Mansharamani et al., who reported more pleuritic chest pain in immunocompetent patients hospitalized with a lung abscess [6]. In our study, the right lower lobe was the most frequently affected lung segment (in $33 \%$ of patients), contrary to what Mansharamani et al. observed [6]. This difference can be explained by the exclusion of mycobacterial infections from our study, which clearly mainly affect apical segments of the lung [27]. Moreover, the large proportion of alcoholism (40\%) and other aspiration risks (14\%) in our study, led to aspiration of oral secretion when unconscious, and concerned particularly the right lower lobe since anatomically the right bronchus is straighter than left.

Our microbiological data show that $S$. aureus and $P$. aeruginosa were the two main bacteria isolated in lung abscesses, as in the Mansharamani et al. study [6]. Streptococcus spp. appeared as the principal bacteria identified in community-acquired lung abscesses [13] and was the third most frequent in our study, which combines nosocomial and community-acquired lung abscesses. Early reports identified multiple species of anaerobic bacteria in lung abscess on regular basis [7, 28-31] whereas recent studies as ours found anaerobes in a substantially lower proportion in favour of aerobes [14, 32-34]. The increasing wide-spectrum empiric antibiotic treatment before bacteriological study in daily practice, impacting particularly anaerobic bacteria, could explain this difference [35].

The mortality rate of lung abscess patients can vary widely, from 1 to $20 \%$, depending on the study $[4,6$, $9-13,15-17]$. We have shown that larger abscesses correlate with a poorer prognosis as described in previous studies $[15,17]$. Moreover, we confirmed that lung abscesses caused by $S$. aureus, Klebsiella pneumoniae, or $P$. aeruginosa are also associated with poor prognosis as described by Hirshberg et al. [17]. In our study, outcomes were assessed not only by mortality, but also relapse and radiological 
sequelae rates. The relapse rate was higher in patients with emphysema. We observed radiographical sequelae in $47 \%$ of patients. This high rate is close to the one (49\%) recently published in children [36]. Radiological sequelae were more frequently observed in patients with bronchogenic abscesses and when spontaneous discharge occurred. In addition to antibiotic treatment, open drainage and/or surgery may be necessary to cure certain patients. The use of these techniques varies widely depending on the study, as open drainage and surgery were performed in 1 to $94 \%$ and 2 to $41 \%$ of patients, respectively $[6,12$, 13]. In our study, open drainage was performed in $14 \%$ of patients and surgery in $3 \%$, without a significant impact on outcomes. Open drainage provided bacterial identification and was preferentially performed when pleural effusion complicated the lung abscess. There is no consensus on the duration of antibiotic treatment and it depends on the clinical and radiological response of the patient. Treatment should obviously be administered until at least fever, putrid sputum, and abscess fluid have resolved. According to expert opinions, the rate of therapeutic failure including relapse, is low if antibiotic therapy is pursued until radiographical changes to a normal range [37]. This may require a total duration of 28 to 48 days, as suggested in a previous study [13]. Expert opinions recommend a prolonged antibiotic therapy over 6 weeks to prevent therapeutic failure [38], our study is the only to confirm poor outcomes in patients treated for less than 6 weeks.

The limitations of this study included its retrospective nature, its being a single-centre study, and the small number of patients. Moreover, the 20 -year period of the study may have complicated the interpretation of the results, given the considerable improvements in both diagnosis and treatment of lung abscesses from 1998 to 2018.

This study indicates that the clinical and radiological presentations of lung abscesses are the main parameters which determine bacterial identification, and outcomes. We suggest that this presentation should guide empirical antibiotic treatment. The prognosis of patients was globally unfavourable when the presentations were bronchogenic and the treatment duration less than 6 weeks. These data should be considered when proposing guidelines for the care of patients with lung abscesses.

\section{Declarations}

\section{Ethics approval and consent to participate:}

The study protocol is conformed to the ethical guidelines of the 1975 Declaration of Helsinki (revised in Edinburgh in 2000), as reflected by a priori approval by the institution's human research committee.

\section{Consent for publication:}

All authors agreed to publish the study.

\section{Availability of data and materials:}


The datasets used and analysed during the current study are available from the corresponding author on reasonable request.

\section{Competing interests:}

The authors declare no conflict of interest in relation to this article

\section{Funding:}

The authors did not receive specific grant for this study

\section{Authors' contributions:}

Study conceptualization and design: TM, LL and GP, Data collection: TM and MH, Statistical analysis: VO, MH and TM, Interpretation of results: TM, JC and GP, Manuscript preparation: TM, GP, JC and VO. Approval for final version of the manuscript: All authors.

\section{References}

1. Bartlett JG, Finegold SM. Anaerobic pleuropulmonary infections. Medicine (Baltimore). 1972;51:41350.

2. Takaro T, Scott SM, Bridgman AH, Sethi GK. Suppurative diseases of the lungs. Pleurae and pericardium. Curr Probl Surg. 1977;14:1-62.

3. Seo H, Cha S-I, Shin K-M, Lim J, Yoo S-S, Lee J, et al. Focal necrotizing pneumonia is a distinct entity from lung abscess. Respirol Carlton Vic. 2013;18:1095-100.

4. Hagan JL, Hardy JD. Lung abscess revisited. A survey of 184 cases. Ann Surg. 1983;197:755-62.

5. Mori T, Ebe T, Takahashi M, Isonuma H, Ikemoto H, Oguri T. Lung abscess: analysis of 66 cases from 1979 to 1991. Intern Med Tokyo Jpn. 1993;32:278-84.

6. Mansharamani N, Balachandran D, Delaney D, Zibrak JD, Silvestri RC, Koziel H. Lung abscess in adults: clinical comparison of immunocompromised to non-immunocompromised patients. Respir Med. 2002;96:178-85.

7. Bartlett JG, Gorbach SL, Tally FP, Finegold SM. Bacteriology and treatment of primary lung abscess. Am Rev Respir Dis. 1974;109:510-8.

8. Lord FT. Certain aspects of pulmonary abscess, from analysis of 227 cases. Boston Med Surg J. 1925;

9. Weiss W, Cherniack NS. Acute nonspecific lung abscess: a controlled study comparing orally and parenterally administered penicillin G. Chest. 1974;66:348-51. 
10. Weiss W. Oral antibiotic therapy of acute primary lung abscess: comparison of penicillin $\mathrm{G}$ and tetracycline. Curr Ther Res Clin Exp. 1970;12:154-60.

11. Weiss W. Delayed cavity closure in acute nonspecific primary lung abscess. Am J Med Sci. 1968;255:313-9.

12. Moreira J da S, Camargo J de JP, Felicetti JC, Goldenfun PR, Moreira ALS, Porto N da S. Lung abscess: analysis of 252 consecutive cases diagnosed between 1968 and 2004. J Bras Pneumol Publicacao Of Soc Bras Pneumol E Tisilogia. 2006;32:136-43.

13. Takayanagi N, Kagiyama N, Ishiguro T, Tokunaga D, Sugita Y. Etiology and outcome of communityacquired lung abscess. Respir Int Rev Thorac Dis. 2010;80:98-105.

14. Kuhajda I, Zarogoulidis K, Tsirgogianni K, Tsavlis D, Kioumis I, Kosmidis C, et al. Lung abscessetiology, diagnostic and treatment options. Ann Transl Med. 2015;3:183.

15. Harber P, Terry PB. Fatal lung abscesses: review of 11 years' experience. South Med J. 1981;74:2813.

16. Pohlson EC, McNamara JJ, Char C, Kurata L. Lung abscess: a changing pattern of the disease. Am J Surg. 1985;150:97-101.

17. Hirshberg B, Sklair-Levi M, Nir-Paz R, Ben-Sira L, Krivoruk V, Kramer MR. Factors Predicting Mortality of Patients With Lung Abscess. Chest. 1999;115:746-50.

18. R Core Team. R: A language and environment for statistical computing. R Found Stat Comput Vienna Austria. 2018;

19. Fernández-Sabé N, Carratalà J, Dorca J, Rosón B, Tubau F, Manresa F, et al. Efficacy and safety of sequential amoxicillin-clavulanate in the treatment of anaerobic lung infections. Eur $\mathrm{J}$ Clin Microbiol Infect Dis Off Publ Eur Soc Clin Microbiol. 2003;22:185-7.

20. Germaud P, Poirier J, Jacqueme P, Guerin JC, Benard Y, Boutin C, et al. [Monotherapy using amoxicillin/clavulanic acid as treatment of first choice in community-acquired lung abscess. Apropos of 57 cases]. Rev Pneumol Clin. 1993;49:137-41.

21. Denu RA, Patel D, Becker BJ, Shiffler T, Kleinschmidt P. MRSA Septicemia With Septic Arthritis and Prostatic, Intraretinal, Periapical, and Lung Abscesses. WMJ Off Publ State Med Soc Wis. 2020;119:62-5.

22. Gin A, Dilay L, Karlowsky JA, Walkty A, Rubinstein E, Zhanel GG. Piperacillin-tazobactam: a betalactam/beta-lactamase inhibitor combination. Expert Rev Anti Infect Ther. 2007;5:365-83.

23. Takayanagi N, Kagiyama N, Ishiguro T, Tokunaga D, Sugita Y. Etiology and outcome of communityacquired lung abscess. Respir Int Rev Thorac Dis. 2010;80:98-105.

24. Moreira J da S, Camargo J de JP, Felicetti JC, Goldenfun PR, Moreira ALS, Porto N da S. Lung abscess: analysis of 252 consecutive cases diagnosed between 1968 and 2004. J Bras Pneumol Publicacao Of Soc Bras Pneumol E Tisilogia. 2006;32:136-43.

25. Mansharamani N, Balachandran D, Delaney D, Zibrak JD, Silvestri RC, Koziel H. Lung abscess in adults: clinical comparison of immunocompromised to non-immunocompromised patients. Respir 
Med. 2002;96:178-85.

26. Hirshberg B, Sklair-Levi M, Nir-Paz R, Ben-Sira L, Krivoruk V, Kramer MR. Factors predicting mortality of patients with lung abscess. Chest. 1999;115:746-50.

27. Aktoğu S, Yorgancioglu A, Cirak K, Köse T, Dereli SM. Clinical spectrum of pulmonary and pleural tuberculosis: a report of 5,480 cases. Eur Respir J. 1996;9:2031-5.

28. Bartlett JG. Anaerobic bacterial infections of the lung and pleural space. Clin Infect Dis Off Publ Infect Dis Soc Am. 1993;16 Suppl 4:S248-255.

29. Glauser FL, Bartlett RH. Pneumoperitoneum in association with pneumothorax. Chest. 1974;66:53640.

30. Kapila R, Sen P, Salaki J, Louria DB. Evaluation of clindamycin and other antibiotics in the treatment of anaerobic bacterial infections of the lung. J Infect Dis. 1977;135 Suppl:S58-64.

31. Gudiol F, Manresa F, Pallares R, Dorca J, Rufi G, Boada J, et al. Clindamycin vs penicillin for anaerobic lung infections. High rate of penicillin failures associated with penicillin-resistant Bacteroides melaninogenicus. Arch Intern Med. 1990;150:2525-9.

32. Wang J-L, Chen K-Y, Fang C-T, Hsueh P-R, Yang P-C, Chang S-C. Changing Bacteriology of Adult Community-Acquired Lung Abscess in Taiwan: Klebsiella pneumoniae versus Anaerobes. Clin Infect Dis. $2005 ; 40: 915-22$.

33. Allewelt M, Schüler P, Bölcskei PL, Mauch H, Lode H, Study Group on Aspiration Pneumonia. Ampicillin + sulbactam vs clindamycin +/- cephalosporin for the treatment of aspiration pneumonia and primary lung abscess. Clin Microbiol Infect Off Publ Eur Soc Clin Microbiol Infect Dis. 2004;10:163-70.

34. DiBardino DM, Wunderink RG. Aspiration pneumonia: a review of modern trends. J Crit Care. 2015;30:40-8.

35. Bartlett JG. The role of anaerobic bacteria in lung abscess. Clin Infect Dis Off Publ Infect Dis Soc Am. 2005;40:923-5.

36. Wojsyk-Banaszak I, Krenke K, Jończyk-Potoczna K, Ksepko K, Wielebska A, Mikoś M, et al. Long-term sequelae after lung abscess in children - Two tertiary centers' experience. J Infect Chemother Off $J$ Jpn Soc Chemother. 2018;24:376-82.

37. Allewelt M. Aspiration pneumonia and primary lung abscess: diagnosis and therapy of an aerobic or an anaerobic infection? Expert Rev Respir Med. 2007;1:111-9.

38. Lorber B. Bacterial lung abscess. 7th ed. Philadelphia: Churchill Livingstone Elsevier; 2010.

\section{Figures}




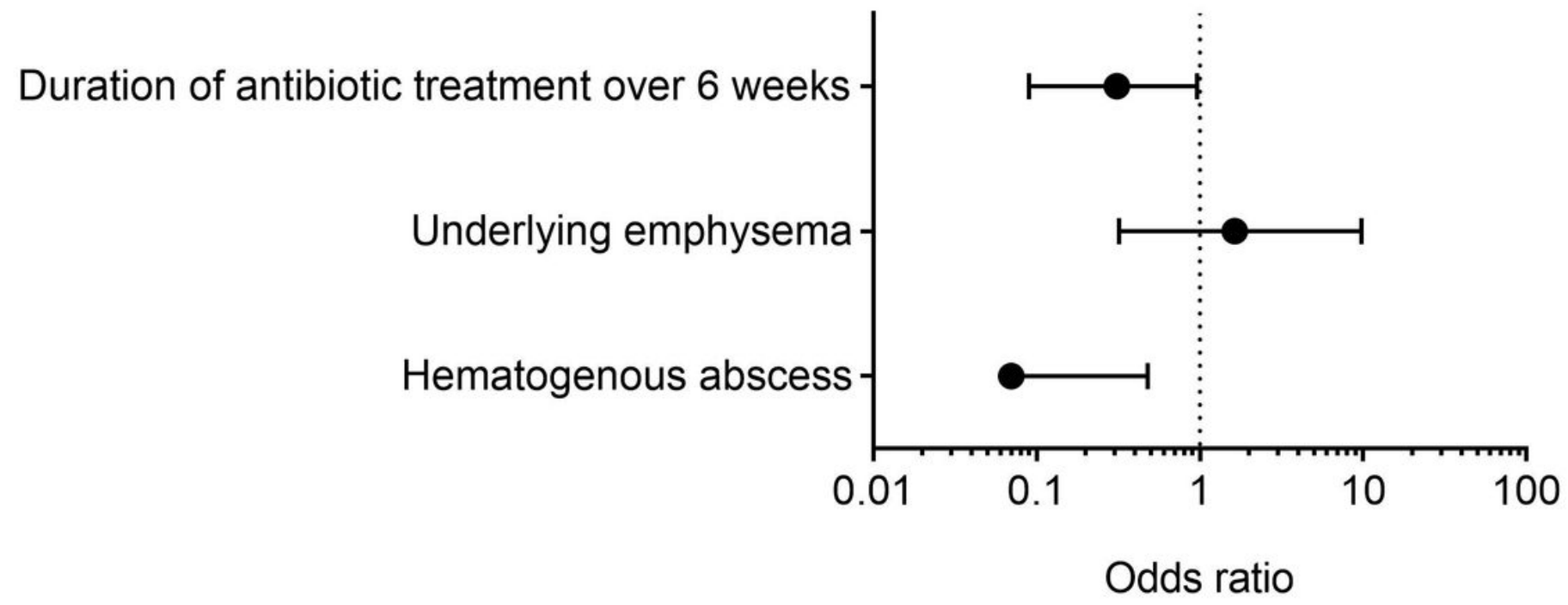

Figure 1

Multivariate analysis of poor outcomes in 64 patients hospitalized with pyogenic lung abscess 